\title{
SUBSÍDIOS SOB A ÓTICA DO DIREITO INTERNACIONAL ECONÔMICO
}

\author{
Karla Margarida* \\ karlasantos@uol.com.br
}

\begin{abstract}
RESUMO
O arranjo oligopolizado de diversos segmentos de mercado em todo o mundo gera uma interdependência entre as empresas, que não reagem mais a forças impessoais provenientes do mercado, mas pessoalmente a suas rivais, reforçando as distorções encontradas nessas estruturas de mercado e possibilitando o alcance de lucros supracompetitivos. A concessão de subsídios por membros da OMC perpassa não apenas por questões ligadas à defesa comercial e comprometidas com a liberalização comercial, mas também por questões concorrenciais, diante da possibilidade de utilização de subsídios como instrumento de alcance de fins anticompetitivos, reforçada pela ausência de norma em vigor no âmbito da OMC que contemple a proteção da concorrência.
\end{abstract}

Palavras-Chaves: Subsídios; Conduta anticompetitiva

Subsidies on the view of International Economic Law

\begin{abstract}
The oligopolized arrangement of different market segments all over the world creates interdependence among firms that do not react against the non personal market power, but personally to their rivals, strengthing the pervasive distortions of these markets structures, making possible to some firms reach overcompetitive profits. The subsidization by WTO members deals not only with matters concerned with commercial defense and commercial liberalization, but also with competitiveness, since subsidies can be used as a stool to reach anticompetitive results, strengthened by the lack of legislation in the WTO scope, concerning to competitive regulation.
\end{abstract}

Keywords: Subsidies; Anticompetitive behavior

\footnotetext{
* Professora do UNICEUB. Pesquisadora do Grupo Integrado de Pesquisa em Direito Internacional Econômico em Sistemas de Integração. Procuradora federal, lotada no CADE desde 1996, aonde responde pela Chefia de Estudos e Pareceres. Mestranda em Direito das Relações Internacionais; Especialista em Direito Econômico e Das Empresas (FGV), Bacharel em Direito pelo UniCEUB; Bacharel em Administração de Empresas pela UnB; Licenciada para magistério profissionalizante pela Universidade Católica de Brasília, tendo cursado a Escola da Magistratura do Distrito Federal.
} 


\section{Introdução}

Como signatário da declaração ministerial de Doha, no Qatar, em 14 de dezembro de 2001, o Brasil tem se mostrado um partícipe ativo das negociações que têm por objetivo incrementar o comércio mundial, imprimindo esforços na melhoria de condições de acesso aos mercados, bem como na eliminação progressiva de subsídios à exportação, elementos considerados nocivos ao salutar processo competitivo, em âmbito mundial.

A Rodada Uruguai caracterizou-se pelo alcance e definição de temas importantes para o comércio mundial, destacando-se a definição de subsídios.

$\mathrm{Na}$ rodada de Tóquio, apesar de ter se objetivado impedir a utilização de subsídios como prática nociva ao comércio entre os Estados membros, não se logrou êxito em definir como seriam aplicados os subsídios domésticos, cuja utilização também repercute no comércio transnacional.

Desde o estabelecimento do Acordo Geral de Tarifas e Comércio (General Agreement on Trade and Tariffs - GATT) verifica-se um propósito de criação de um mercado globalizado, com a manifesta intenção de eliminação de artifícios impeditivos ao livre comércio, como os subsídios, cuja consolidação foi anunciada com a criação da Organização Mundial do Comércio (OMC) em 1998, com base em um sistema de normas que objetiva garantir aos seus membros a segurança jurídica necessária para o incremento do comércio internacional entre firmas e nações.

O processo de globalização teve uma grande evolução com o incremento de acumulação de capitais e sua internacionalização, possibilitando a empresas, nações e indivíduos investirem em países onde não estejam fisicamente instalados, atribuindo um novo perfil à distribuição de capitais e ao poder dela decorrente.

No que tange às empresas e aos países detentores de um nível de renda elevado, pode-se dizer que a concentração de capitais em suas mãos viabiliza a formulação de estudos e cenários econômicos que lhes dão projeções seguras acerca do processo decisório, minimizando os riscos e viabilizando não apenas o acerto, mas muitas vezes uma concentração cada vez mais incisiva de capitais nas mãos de pequenos grupos, gerando os denominados oligopólios e possíveis distorções decorrentes, como os cartéis transnacionais. 
A estrutura de mercado prevalecente em praticamente todo o mundo é extremamente oligopolizada, gerando uma interdependência entre as empresas, que já não reagem mais a forças impessoais provenientes do mercado, mas sim pessoalmente a suas rivais ${ }^{1}$, no intuito de concentrar cada vez mais a oferta de produtos e serviços, podendo, por força das distorções, auferir lucros supracompetitivos. Diversos Estados têm interesse de que as empresas instaladas em seus territórios respondam por parcela significativa da oferta de produtos. O auxílio estatal, consubstanciado muitas vezes na forma de subsídios, revelase tentador às empresas que passam a auferir lucros de forma mais vantajosa que as firmas instaladas em outros países. Para os países a concessão de subsídios pode representar não apenas a circulação de mais capital em sua economia, com a geração de empregos, recolhimento de tributos e incremento das exportações, mas forte instrumento de barganha em processos de sucessão política.

Há muitas dificuldades no procedimento de investigação e punição de cartéis internacionais, provenientes das divergências encontradas nas legislações de cada país e, muitas vezes, da ausência de interesses desses entes estatais em, na verdade, ver punidas empresas que estão contribuindo, mesmo que com práticas questionáveis, para o crescimento de suas economias nacionais.

Outro fator que causa preocupação no cenário internacional e de certa forma, conseqüente do processo de globalização, diz respeito à capacidade de alguns governos de sustentarem práticas anticompetitivas via preços subsidiados, o que torna práticas comerciais subsidiadas por governos muitas vezes mais perigosas do que o dumping propriamente dito. De fato, alguns governos possuem condições de sustentar uma prática anticoncorrencial por mais tempo e de forma mais sutil do que muitas empresas privadas, via preços subsidiados, inclusive por intermédio da concessão de incentivos fiscais a empresas sem a menor vantagem competitiva ${ }^{2}$.

Não se pode negar, por conseguinte, que deve ser dada maior ênfase a processos em que a participação governamental está presente, haja vista a possibilidade de dano à indústria doméstica do país importador, diante da competição com produtos subsidiados.

\footnotetext{
${ }^{1}$ CHESNAIS, François. A Mundialização do capital. São Paulo: Xamã, 1996, p. 92.

2 JOHANNPETER, Guilherme Chagas Gerdau. Antidumping: prática desleal no comércio internacional. Porto Alegre: Livraria do Advogado, 1986, p. 96.
} 
Apesar de algumas práticas consideradas desleais no comércio como subsídios repercutirem de forma significativa no cenário concorrencial, não há nenhuma norma em vigor no âmbito da OMC que contemple a proteção da concorrência.

O presente trabalho pretende demonstrar que os subsídios podem constituir uma forma de dano à indústria doméstica do país importador, haja vista o auxílio dos governos de sustentar uma determinada prática via preços subsidiados, contribuindo, muitas vezes para a criação ou reforço de figuras nocivas como os cartéis transnacionais. Para tanto, é feita uma análise da legislação que trata de subsídios, apresentando-se sua definição e classificação, comentando-se ao final recentes decisões da OMC sobre o tema.

\section{Subsídios}

\subsection{Origem remota}

Há vários relatos na história econômica de intervenções efetuadas pelos Estados Nacionais em situações tipicamente comerciais como forma de proteção de interesses nacionais e de expressão de poder, nos impérios gregos e romanos ${ }^{3}$.

A adoção de algumas medidas protecionistas era justificada pela geração de riquezas à economia aos Estados, o que fomentava o desenvolvimento comercial, inclusive para além das fronteiras, exteriorizando-se durante diversos séculos por intermédio de modelos como o mercantilista.

No século XVII, o modelo capitalista de produção efetua uma revolução em diversos cenários das relações economias. A produção passa a ser voltada para o mercado, não se fazendo mais presente a atuação estatal protecionista. Rompe-se, o modelo dirigido pela vontade estatal, estando o novo modelo calcado na liberdade de atuação e na concorrência de mercado.

Em 1776 Adam Smith, escreve "A Riqueza das Nações”, obra em que defende a produção voltada para o mercado livre da atuação do Estado. O pensamento liberal de Adam Smith postula a atuação da mão invisível do mercado, fornecendo o Estado a base legal para a promoção de uma maior liberdade de atuação dos agentes nele instalados, tornando-lhes possível o alcance de maior bem-estar pelas condições adquiridas pelo seu desempenho nas relações mantidas por força de seus trabalhos. No cenário internacional, os

\footnotetext{
${ }^{3}$ HUGON, Paul. História das doutrinas econômicas. São Paulo, Editora Atlas, 1980, p. 339.
} 
liberais postulam a eliminação das barreiras ao comércio internacional, sob a crença de que seriam assim reduzidos os custos de transações, levando a um maior desenvolvimento das economias envolvidas.

O tema, entretanto, está longe de ser pacífico. O surgimento da escola do Intervencionismo Nacional, em meados do século XIX, defendendo a substituição do livrecambismo por uma política protencionista, retornando o fator nação a assumir novamente papel primordial, é uma reação ao liberalismo ${ }^{4}$. Apesar das discussões no campo teórico quanto às vantagens ou desvantagens do liberalismo, o livre comércio entre as nações ganhou renovado fôlego após a Segunda Guerra Mundial.

\subsection{Disciplina no GATT}

A tentativa de criação de um órgão regulamentador do comércio internacional remonta ao encontro de Bretton Woods, no final da II Grande Guerra, quando os países do bloco vencedor previram a criação de organismos internacionais como o Fundo Monetário Internacional (FMI), o Banco Mundial e a Organização Internacional do Comércio (OIC). ${ }^{5}$

A Carta de Havana de 1948 tentou delimitar os objetivos e funções da Organização Internacional do Comércio, restando infrutíferos os esforços diante da não ratificação do texto pelo congresso norte-americano, onde se encontrava, à ocasião, uma maioria republicana ${ }^{6}$.

Diante de tal fato, aprovou-se o GATT (General Agreement on Tariffs and Trade), ou o Acordo Geral de Tarifas e Comércio, assinado pelo Brasil ${ }^{7}$ e mais 22 países, constituindo-se, então, no único acordo multilateral com regras destinadas ao comércio internacional, objetivando não apenas a redução das tarifas alfandegárias no comércio internacional, mas também sendo mecanismo importante pra a solução de controvérsias e disputas comerciais.

A realização de rodadas periódicas passou a envolver um número cada vez mais crescente de Estados e matérias não tarifárias passaram a ser objeto de negociação. $O$ GATT passou a abranger um conjunto considerável de normas, em diversos setores do

\footnotetext{
${ }^{4}$ HUGON, p. 345.

${ }^{5}$ BARRAL, Weber (org.). O Brasil e a OMC. Curitiba, Juruá, 2002, p. 12.

${ }^{6}$ Ibidem.

${ }^{7}$ Incorporado pelo nosso ordenamento jurídico pela Lei 313/48.
} 
comércio internacional, por intermédio de uma prática consolidada de negociação e de solução de controvérsias (panels). Em referido acordo verifica-se ainda a preocupação com a concessão de subsídios tidos como incompatíveis com o livre comércio, com a condenação determinada no artigo VI do GATT.

$\mathrm{O}$ artigo XVI do GATT contém regras gerais acerca de subsídios. Por ocasião da formação do GATT, a redação do artigo XVI tinha uma única disposição cujo propósito era encorajar a notificação e consulta acerca do uso de subsídios. A seção A estabelece que as partes devem notificar o GATT acerca de qualquer subsídio que afete as importações ou exportações, ainda que indiretamente, bem como o de indicar qual interesse está sendo maculado ou sofrendo um grave dano por força dos subsídios.

Em 1955, houve o acréscimo de normas relativas a subsídios de exportação, com a distinção de produtos primários e não primários $^{8}$. De acordo com a redação do referido dispositivo, as partes eram obrigadas a tentar evitar o uso de subsídios na exportação de produtos primários, na medida em que a utilização desse tipo de subsídios pudesse propiciar a aquisição de uma parcela mais que razoável na exportação do produto. Com relação aos produtos não-primários, as partes deveriam evitar o uso de subsídios que resultassem na exportação de produtos a preços inferiores aos preços praticados para venda no mercado doméstico. A distinção entre produtos primários e não-primários foi interpretada pelos países em desenvolvimento como uma forma de discriminação contrária aos interesses comerciais dessas nações, que por esse motivo a ela não aderiram.

\subsection{Rodada de Tóquio}

Na Rodada de Tóquio (1979) elabora-se o Código de Subsídios, que alargou o conceito de subsídio, incluindo a indústria doméstica e adotando um sistema de consultas e resolução de controvérsias. Os EEUU, no entanto, insistiram que as regras de salvaguardas só pudessem ser utilizadas caso se alcançasse um acordo para disciplinar de forma mais genérica o assunto. Na verdade, havia uma diferença fundamental entre a abordagem de subsídios e medidas compensatórias. O resultado desse conflito entre os EEUU e os demais países resultou nas duas etapas de negociação levadas a efeito em Tóquio.

\footnotetext{
${ }^{8}$ CASELLA, Paulo Borba e MERCADANTE, Araminta de Azevedo (coord). Guerra Comercial ou integração mundial pelo Comércio? São Paulo: LTr, 1998, p. 373.
} 
A primeira etapa de negociações tratou da imposição de medidas de salvaguarda a produtos importados subsidiados que estivessem causando prejuízo à indústria doméstica. Os assinantes do acordo poderiam impor medidas de salvaguarda suficientes para deter subsídios estrangeiros, ou diminuir os impostos, caso isso fosse suficiente para aliviar o prejuízo. $\mathrm{Na}$ verdade, os procedimentos então previstos se aproximavam bastante aos utilizados em hipóteses de antidumping. A principal falha no Código foi de não contemplar uma definição clara acerca de um subsídio acionável, atribuindo aos países uma grande margem de manobra na utilização de medidas de salvaguarda.

A segunda etapa de negociações ocorrida na Rodada de Tóquio preocupou-se em definir os subsídios que distorciam as práticas comerciais dos Estados e, para a maioria, essa etapa foi uma forma de elaborar-se a redação do artigo XVI do GATT. Os Estados acordaram em consultar os demais Estados membros que aderiram ao instrumento na hipótese de utilização de qualquer subsídio que pudesse causar impactos às importações ou exportações de outros membros, inclusive em outros produtos que não os primários. Além disso, no que se refere aos produtos primários, os signatários deveriam evitar sua utilização caso esses servissem para incrementar de forma significativa e não justificada o comércio do país, durante um período significativo. Se o subsídio estivesse sendo mantido de uma forma que violasse dispositivos do Código, um signatário poderia requerer uma consulta questionando a conduta do Estado ofensor de acordo com o artigo 12(1). Caso não fosse alcançada uma decisão consensual entre as partes em trinta dias, o problema seria submetido a um painel (parte VI do Código).

O artigo 11 do Código definiu subsídios domésticos no mesmo sentido que o artigo XVI do GATT, oportunidade em que os países signatários reconhecem que subsídios domésticos podem constituir importantes instrumentos de políticas sociais e econômicas:

- no intuito de eliminar desigualdades da indústria, social ou econômica de diferentes regiões;

- para facilitar a reestruturação, em consonância com condições socialmente aceitáveis, de determinados setores, especialmente naqueles em que tal fato seja necessário por força de modificações nas políticas comercial e econômica, inclusive provenientes de acordos comerciais que resultem em menores barreiras ao comércio; 
- para manter o nível de empregos e fomentar o treinamento de mão-de-obra e mudanças de postos de trabalho;

- para estimular programas de pesquisa e desenvolvimento, especialmente em indústrias de alta tecnologia;

- para implementar políticas e programas econômicos que promovam o desenvolvimento econômico e social de países em desenvolvimento;

- para reorganização industrial no intuito de impedir danos ambientais.

Na verdade, a intenção dos signatários na Rodada de Tóquio não foi a de engessar a capacidade dos diversos Estados de utilizar subsídios quando tal artifício se demonstrasse importante para o alcance de seus objetivos políticos e sociais. Deveria o Estado-membro repensar sua política concessão de subsídios caso a mesma viesse a causar dano a indústria doméstica de outro Estado-membro ou grave prejuízo a seus interesses, ou ainda, a nulidade ou prejuízo dos benefícios de outro signatário. Na prática, o Código de Subsídios formulado na Rodada de Tóquio, apesar de ampliar sua conceituação, com a inclusão da indústria doméstica e com a adoção de um sistema de consultas e resolução de controvérsias, foi firmado por apenas 24 Estados dos 102 participantes $^{9}$, tendo restado como um Estatuto de pouca aceitação e aplicabilidade ${ }^{10}$.

\subsection{Rodada do Uruguai - Acordo sobre Subsídios e Medidas Compensatórias}

Iniciada em 1986 e concluída em 1994, a Rodada do Uruguai resultou na criação da Organização Mundial do Comércio (OMC) e no aperfeiçoamento dos Códigos sobre Subsídios e Medidas Antidumping, entre outros.

Um dos grandes avanços ocorridos na Rodada do Uruguai diz respeito à definição de subsídios à exportação, com a negociação de um novo Acordo sobre Subsídios e Medidas Compensatórias. (ASMC). É no âmbito desta Rodada que se define o conceito de subsídios, passando a OMC faz uso do single undertaking, ou seja, as negociações levadas a efeito pelos membros da instituição passam a ser obrigatórias aos seus integrantes. Os

\footnotetext{
${ }^{9}$ De acordo com dados da OMC in www.wto.org/english/thewto_e/whatis_e/tif_e/fact4_e.thm, acesso em 14.10.2004

${ }^{10}$ TREBILCOCK, Michael e HOWSE, R. The regulation of international trade. Londres: Routledge, 2001. p. 192-193.
} 
acordos e tratados discutidos no âmbito da OMC passam a ser multilaterais, extinguindo-se a possibilidade de adesão apenas a alguns acordos, como acontecia no GATT (GATT à la carte). Amplia o acordo a lista de subsídios proibidos, reforça a disciplina dos subsídios domésticos e define quais subsídios podem ser usados ${ }^{11}$.

O ASMC foi incorporado ao ordenamento jurídico brasileiro por intermédio do Decreto 1.355/94 e o Decreto 1.751/95, estabelecendo os procedimentos às empresas para solicitar ao governo brasileiro a aplicação de medidas compensatórias previstas no Acordo, quando importações de produtos subsidiados originários de países integrantes da OMC causem danos a indústria nacional.

\subsection{Definição}

De acordo com o Acordo sobre Subsídios e Medidas Compensatórias (ASMC), caracteriza-se a presença de subsídios caso exista a contribuição financeira por um governo ou organismo público em que haja a transferência direta de fundos, potenciais transferências diretas de fundos ou obrigações; quando houver remissão de receitas públicas ou deixarem essas de ser recolhidas; quando o governo forneça ou adquira bens ou serviços além daqueles destinados à infra-estrutura, ou ainda, quando efetue pagamentos a um sistema de fundo ou confie ou instrua órgão privado a realizar qualquer das formas de apoio anteriormente citadas.

Além da contribuição ou auxílio estatal, deve ficar caracterizada uma vantagem para quem recebe o benefício e que esta seja específica a uma empresa ou setor em particular, devendo a especificidade ser fundamentada em provas positivas.

A definição de especificidade passa a ter um papel relevante na determinação da ilegalidade da concessão do subsídio $^{12}$, sendo adotada nesta Rodada a definição na legislação norte-americana de salvaguarda.

A classificação dos subsídios como uma prática condenável no âmbito do comércio internacional é tema de grandes controvérsias, haja vista que muitos Estados consideram que é seu papel intervir na economia com o intuito de promover o desenvolvimento

\footnotetext{
${ }^{11}$ THORSTENSEN, Vera. OMC - Organização Mundial do Comércio. São Paulo: Aduaneiras, 2001, p. 133.

${ }^{12}$ CASELLA, Paulo e MERCADANTE, Araminta (org.). Guerra Comercial Ou Integração Mundial pelo Comércio?

BARRAL, Weber. Subsídios e Medidas Compensatórias na OMC. p. 375.

TREBILCOCK e HOWSE, The Regulation of International Trade. Londres: Routledge, 2001, p. 195.
} 
nacional. Nesta linha, os subsídios são vistos como um instrumento fundamental (e legítimo) em tal missão ${ }^{13}$. Tais diferenças refletiram-se nas negociações do GATT, resultando no enquadramento das diversas formas de subsídios, pelo Acordo de Subsídios e Medidas Compensatórias (ASRU), como se passará a analisar.

\subsection{Categorias}

O ASMC define três categorias de subsídios: proibidos, recorríveis e irrecorríveis, também conhecidos como vermelhos, amarelos e verdes, respectivamente.

\subsubsection{Subsídios Proibidos}

De acordo com o art. $3^{\circ}$, caracterizam-se como subsídios proibidos aqueles vinculados de fato ou de direito ao desempenho exportador e ao uso preferencial de produtos nacionais em detrimento de produtos estrangeiros, quer seja individualmente, quer como parte de um conjunto de condições. Por proibidos que são, nenhum membro poderá conceder ou manter subsídios dessa espécie (art. $\left.3^{\circ}, \S 2^{\circ}\right)$.

Ressalte-se que para produtos agrícolas não existe a proibição, mas sim limitações quantitativas previstas no Acordo sobre Produtos Agrícolas ${ }^{14}$.

O próprio ASCM fornece uma lista ilustrativa de subsídios proibidos, constante de seu anexo I que contempla:

a) concessão pelos governos de subsídios diretos vinculados ao desempenho de exportações;

b) esquemas de retenção de divisas ou práticas similares que envolvam bônus às exportações;

c) tarifas de transporte interno e de fretes para exportações que sejam mais favoráveis do que as aplicadas aos despachos internos;

d) fornecimento pelo governo ou por entidades governamentais de produtos ou serviços importados ou nacionais, para uso na produção de bens destinados à exportação, em condições mais favoráveis que as de fornecimento de produtos ou serviços similares ou diretamente competitivos para uso na produção de bens destinados ao consumo doméstico, se tais termos ou condições são mais favoráveis do que aqueles comercialmente disponíveis

\footnotetext{
${ }^{13}$ BARRAL, p. 144.

${ }^{14}$ BARRAL, p. 151.
} 
nos mercados mundiais para seus exportadores, ou seja, quando a escolha entre produtos nacionais e importados depende apenas de situações comerciais;

e) isenção, remissão ou diferimento de impostos indiretos sobre etapas anteriores de bens ou serviços utilizados na produção de produtos exportáveis;

f) remissão, isenção de impostos indiretos, além dos incidentes sobre insumos importados e que sejam utilizados na produção de produtos exportáveis;

g) a criação pelo governo de programas de garantias de crédito ou programas de seguro à exportação, bem como de programas de seguro ou garantias contra aumentos no custo de produtos exportados ou programas de proteção contra riscos de flutuação nas taxas de câmbio, cujos prêmios sejam insuficientes para cobrir os custos de longo prazo e as perdas provenientes do programa;

h) concessão de créditos à exportação a taxas inferiores àquelas pelas quais o governo obtém os recursos utilizados, ou pagamento pelo governo da totalidade ou de parte dos custos em que incorrem exportadores ou instituições financeiras na obtenção de crédito, na medida em que sejam utilizados para garantir vantagem significativa na concessão de créditos à exportação, além de qualquer outra despesa para o orçamento público que constitua um subsídio, nos termos do artigo XVI do GATT.

O procedimento a ser utilizado na hipótese de questionamento de utilização de subsídio proibido por um Estado membro está disciplinado no artigo $4^{\circ}$ do ASMC. Após esgotada a tentativa de negociação, ou caso seja a mesma alcançada em trinta dias, poderá ser submetida ao Órgão de Solução de Controvérsias que, por sua vez, pode devolvê-la a um grupo especial. Uma vez estabelecido, o grupo especial poderá solicitar a assistência do Grupo Permanente de Especialistas (GPE). Caso o subsídio em análise seja considerado proibido, o GPE recomendará sua imediata exclusão, com fixação de prazo para adoção dessa providência, em relatório a ser adotado pelo OSC. Não sendo cumprida a decisão do OSC no prazo fixado pelo Grupo Especial, o OSC autorizará o membro reclamante a adotar as contramedidas necessárias.

O procedimento para solução de controvérsias na hipótese de questionamento de utilização de subsídios não acionáveis é bastante próximo ao utilizável aos casos de subsídios proibidos, podendo o membro valer-se consultas ou levar o caso ao Comitê sobre Subsídios, procedimentos esses previstos no Acordo. Dessa forma, caso o membro acredite 
que um determinado programa de subsídios tenha resultados adversos para sua indústria doméstica, pode valer-se de consultas ou ainda, submetê-lo ao Comitê sobre Subsídios que pode recomendar alterações no programa para eliminar os efeitos nocivos causados a outros membros.

\subsubsection{Subsídios Recorríveis}

Os subsídios são considerados recorríveis ou ilegais quando possam causar um efeito danoso à indústria nacional de outro Estado-membro, ou resultem na anulação ou prejuízo de vantagens concedidas direta ou indiretamente por outros membros (art. $5^{\circ}$ ).

No que se refere ao procedimento aplicável no questionamento de utilização de subsídios recorríveis, o membro reclamante deve ter motivos para acreditar que outro membro esteja produzindo dano, anulação, prejuízo ou grave dano à sua indústria nacional $\left(\operatorname{art} .7^{\circ}\right)$. O requerimento também deve incluir provas relativas à existência e natureza do subsídio e o dano causado à indústria ou aos interesses do membro que solicita a consulta. Caso não seja alcançada solução mutuamente satisfatória no prazo de 60 dias, ou em outro prazo convencionado pelas partes, qualquer membro participante da consulta poderá submeter à matéria ao OSC para estabelecimento de grupo especial. Caso o OSC decida pela instalação de um grupo especial, o relatório emitido por esse último será submetido às partes em litígio e circulará entre todos os membros, no prazo de 120 dias. No prazo de 30 dias a contar da divulgação do relatório, esse será adotado pelo OSC, a não ser que uma das partes notifique formalmente sua intenção de apelar.

$\mathrm{Na}$ hipótese de apelação do relatório do grupo especial, o Órgão de Apelação emitirá sua decisão no prazo de 60 dias a contar da data em que o membro litigante comunicou sua decisão de apelar. Caso seja adotado o relatório do grupo especial ou do Órgão de Apelação em que se conclua que um subsídio resultou em efeitos danosos aos interesses de outro membro, deve o membro outorgante dos subsídios adotar as medidas cabíveis para sua remoção. Se tais providências não forem adotadas em 6 (seis) meses, a contar da data em que o OSC adotar o relatório do grupo especial ou do Órgão de Apelação, o OSC autorizará o membro reclamante a adotar contramedidas, proporcionais ao grau e à natureza dos efeitos danosos causados. 


\subsubsection{Subsídios Irrecorríveis}

Subsídios irrecorríveis, ou permitidos, são considerados, nos termos do art. $8^{\circ}$, os não específicos e os que, mesmo sendo específicos, sejam destinados à assistência para atividades de pesquisa realizada por empresas ou estabelecimentos de pesquisa ou de educação superior, desde que o apoio não abranja mais do que $75 \%$ dos custos de pesquisa ou $50 \%$ dos custos de atividade pré-competitivas de desenvolvimento, como por exemplo, formulação de desenho de alternativas a produtos, não contemplando alterações rotineiras nos produtos existentes, nas linhas de produção ou serviços oferecidos; assistência a região economicamente desfavorecida, assim considerada a partir de critérios neutros e objetivos, definidos em lei ou outro documento oficial, devendo a região geográfica ser claramente identificável, com identidade econômica e administrativa definível.

Caracterizam-se como subsídios permitidos a assistência para que se efetue adaptações nas instalações existentes a novas exigências ambientais, impostas por lei, que resultem em maior encargo financeiro para a empresa, desde que tal auxílio seja excepcional e não recorrente, limitado a $20 \%$ do custo de adaptação e não cubra os custos de reposição e operação do investimento, que devem recair inteiramente sobre as empresas. Deve o apoio, ainda, estar disponível a todas as firmas que possam se valer do novo equipamento.

O procedimento aplicável na hipótese de questionamento de subsídios irrecorríveis é bastante próximo das regras de questionamento de subsídios proibidos, podendo o membro reclamante, caso seja confirmada a utilização desse tipo de subsídio, solicitar seja efetuada consulta ao outro membro ou que lhe seja viabilizada a aplicação de medidas compensatórias.

\subsection{Definição de Dano}

Apesar da previsão normativa do que sejam subsídios permitidos e recorríveis, não basta que o subsídio seja considerado recorrível para que um Membro possa impor medidas compensatórias contra outro. Deve-se demonstrar também que a utilização de tais subsídios está efetivamente causando um dano ao país importador, uma ameaça de dano ou um atraso na implantação de uma indústria nacional. 
O próprio ASMC define os casos de grave dano. Esse ocorrerá quando o subsídio total a um produto calculado ad valorem $^{15}$ for superior a $5 \%$; quando forem destinados a cobrir prejuízos operacionais incorridos por uma empresa, a não ser que se trate de uma medida isolada e não seja recorrente, sendo concedida para desenvolver soluções de longo prazo e evitar graves problemas sociais (art. $\left.6^{\circ}\right)$.

Haverá a caracterização de grave dano aos interesses de outro membro caso o efeito causado pelo subsídio seja deslocar ou impedir a importação de produto similar de outro membro para o mercado do membro que outorga subsídios ou para um terceiro país; provocar a redução significativa do preço do produto subsidiado ou perda de vendas quando comparado com o preço de produto similar oferecido por outro membro, no mesmo mercado; ou ainda quando aumente a participação do membro que fornece subsídios no mercado mundial de produtos primários ou commodities, quando comparada a participação média que esse possuía nos três anos anteriores. A verificação de dano será obtida através da averiguação do comportamento de uma série de fatores. Não há, entretanto, uma estipulação precisa de quando uma deterioração em tais indicadores pode ser entendida como demonstração do dano, contemplando a legislação uma mera lista de fatores que permite indagar a respeito do montante de dano. $\mathrm{O}$ exame deve compreender os fatores possíveis de serem levantados, informações que permitam um exame objetivo do efeito das importações subsidiadas no mercado do produto em questão, no que se refere ao impacto destas importações sobre produtos domésticos ${ }^{16}$.

Portanto, a determinação do dano será decorrente de análise objetiva, baseando-se nos seguintes aspectos:

1) Volume de importações subvencionadas, verificando se houve um aumento significativo em termos absolutos ou em relação à produção ou ao consumo do Membro importador. Caso as importações de mais de um país sejam objeto de investigação de utilização de subsídios, tais importações poderão ser cumuladas se a quantia subvencionada

\footnotetext{
${ }^{15}$ Pode-se considerar o valor ad valorem é o resultado do valor normal, subtraído do preço de exportação, dividido pelo preços CIF de importação. No entanto, não se pode deixar de registrar que há diversos questionamentos por parte de Estados Membros acerca da metodologia de subsidiação ad valorem, o que gera uma instabilidade jurídica ao Acordo sobre Subsídios e Medidas Compensatórias na OMC. Na ausência de consenso entre os países membros, cada um é livre para calcular como quiser, dificultando a verificação por parte dos demais e do próprio Órgão de Solução de Controvérsias de que se está dentro ou fora dos limites de subsidiação proibido. No caso da disputa envolvendo o Brasil e o Canadá, WT/DS177, por exemplo, como se avaliar qual o impacto de um empréstimo do PROEX num avião produzido pela EMBRAER?

16 JOHANNPETER,Gerdau. op. cit., pág. 117.
} 
for superior a uma margem mínima, chamada margem de minimis e a cumulação seja conveniente em função da concorrência entre as diferentes importações, ou entre estas e o similar nacional ${ }^{17}$;

2) Efeito das importações sobre os preços no mercado interno, considerando-se tal efeito como uma subvaloração dos preços nas importações em relação ao produto similar do importador ou se tais importações de qualquer outro modo causarem uma baixa significativa nos preços do produto ou impedirem uma subida de preços que sem tal interferência ocorreria;

3) Repercussão das importações ${ }^{18}$ sobre os produtores nacionais, determinada através da avaliação de todos os índices e indicadores econômicos pertinentes que influam sobre a indústria, em especial o declínio real e potencial das vendas, lucros, volume de produção, participação de mercado, produtividade, retorno sobre o investimento, utilização de capacidade instalada, fatores que afetem os preços domésticos, efeitos reais e potenciais sobre o fluxo de caixa, estoques, emprego, salários, crescimento, capacidade para aumentar capital ou obter investimentos.

4) Ameaça de dano que, por sua vez, deve embasar-se nos seguintes aspectos:

- Uma significativa taxa de crescimento de importações subsidiadas, que indique um aumento substancial das importações;

- Capacidade do exportador ou um iminente aumento das importações que indique um aumento nas importações subsidiadas, considerando-se a existência de outros mercados importadores que poderiam absorver este possível aumento;

- Importações a preços capazes de significativamente reduzir o preço interno ou conter seu aumento e que provavelmente levem a uma demanda por novas importações;

No caso dos subsídios, a natureza dos mesmos e os efeitos que eles provavelmente terão sobre o comércio.

\footnotetext{
${ }^{17}$ No intuito de minimizar assimetrias geradas da aplicação dos termos constantes do Acordo Antidumping (AAD) e do Acordo sobre Subsídios e Medidas Compensatórias (ASMC), o Brasil, com o apoio de outros países apresentou no âmbito do Grupo de Negociação de Regras documento destacando a necessidade de aprimoramento das regras relativas a aplicação de medidas compensatórias e antidumping. Nesse sentido, veja-se o documento TN/RL/W/104, disponível em www.wto.org.

${ }^{18}$ Ainda no que se refere ao intuito de harmonizar as definições constantes do AAD e ASMC, na determinação da do dano causado à indústria doméstica, o Brasil tem defendido que seja proibido o cômputo das importações originárias de empresas para as quais houve determinação de montante de subsídios de minimis, como se verifica no documento TN/RL/W/29.
} 


\subsection{Conceito de nexo causal}

Considera-se necessária a demonstração da existência de nexo causal para que seja imposta uma medida compensatória, além da determinação da existência de dano. $\mathrm{O}$ aumento de importações, portanto, deve ser o motivador do prejuízo ou dano causado no mercado interno de outro membro, devendo basear-se em evidências relevantes, levando-se em consideração qualquer outro fator conhecido que possa estar prejudicando a indústria doméstica, como reduções de demanda, mudanças nos hábitos de consumo, práticas restritivas ao comércio e competição entre produtores estrangeiros e nacionais, inovações tecnológicas, desempenho e produtividade da indústria doméstica, que considerados alheios às importações, não justificam a imposição de medidas compensatórias.

\subsection{Investigação na utilização de subsídios}

Toda e qualquer investigação com vistas a questionar a utilização de subsídios por parte de Estado membro e a conseqüente aplicação de medida compensatória deve ser efetuada pelas autoridades nacionais, prevendo a legislação do país a competência da autoridade nacional para proceder às investigações (art. 14).

O procedimento investigatório deve ser iniciado quando as autoridades verificarem que a solicitação foi feita pela indústria doméstica ou em seu nome (art. 16), quando o conjunto de produtores responder por mais de $50 \%$ da produção total de produto similar ${ }^{19}$. Não pode investigação ser iniciada caso os produtores respondam por parcela inferior a $25 \%$ do total da produção dos produtos similares.

$\mathrm{Na}$ hipótese da quantia de subsídio ser considerada de minimis (art. 11, $\S 9^{\circ}$ ), ou seja, inferior a $1 \%$ ad valorem ou for considerado desprezível o volume de importações, a investigação não tem prosseguimento.

As partes e membros interessados terão ampla oportunidade para apresentar todas as provas consideradas importantes para demonstração da relação causal entre as importações subsidiadas e o dano causado à produção nacional.

\footnotetext{
${ }^{19}$ A definição de produto similar é fundamental na condução da investigação e, conseqüentemente, para a decisão sobre a eventual aplicação de medida. Na verdade, a utilização deve ser restritiva, sob pena de se permitir a inclusão de produtos com características semelhantes, mas que se endereçam a mercados distintos, aplicando-lhes medidas quando nem todos venham a causar dano aos produtores domésticos do produto. Nesse sentido, é interessante o contido no DS 177/178 ABR, disponível em www.wto.org.
} 


\subsection{Importância do tema para os países em desenvolvimento}

O próprio ASMC reconhece a importância do tema subsídios e estabelece as hipóteses em que sua concessão mostra-se condenável. Na redação do art.27 encontram-se regras que preceituam um tratamento especial aos países em desenvolvimento, que pode ser dispensado a países que estão migrando para uma economia de mercado. Por força do contido no art. $27, \S 4^{\circ}$, aos países em desenvolvimento seria possibilitada a utilização de subsídios considerados proibidos pelo período de 08 (oito) $\operatorname{anos}^{20}$. Os países em desenvolvimento com situação enquadrável no disposto no art. $27, \S 2^{\circ}$, (b) teriam a possibilidade de requerer, no máximo em 31.12.01, uma prorrogação do período de transição. Em 2002, o Comitê aprovou solicitações de prorrogação formuladas por 21 países, referentes a programas específicos, em conformidade com o disposto no art. $27, \S$ $4^{\text {o }}$, até 2003 . As solicitações foram baseadas em documentos emanados da etapa de Doha ${ }^{21}$. O Comitê, após examinar a transparência e o status dos programas de subvenção à exportação entendeu ser possível a prorrogação do prazo durante o ano de 2004, a 19 membros.

Não se pode negar, no entanto, que o tratamento diferenciado aos países em desenvolvimento é uma manifestação do princípio da desigualdade compensadora, eis que busca permitir a todos os integrantes da OMC o alcance de uma maior eficiência econômica. Segundo Varella, não há nada de mal em conceder um período mais amplo ou melhores condições a países que se precisam atingir um nível mais elevado de desenvolvimento ${ }^{22}$.

A discussão da concessão de subsídios ganha maior importância ao se verificar que os países em desenvolvimento e os países menos avançados respondem por uma parcela pequena do comércio internacional ${ }^{23}$, basicamente produtos agrícolas e têxteis, que apesar

\footnotetext{
${ }^{20}$ De acordo com CHEREM, Giselda, "seria permitido o subsídio pelo período de cinco anos aos países em desenvolvimento e por oito anos aos países de menor desenvolvimento relativo, desde que a situação desses últimos se enquadrasse no art. $3^{\circ}, \S 1^{\circ}$, (b), ou seja, caracterizando-se como subsídio acionável, contando-se o prazo a partir da entrada em vigor do ASMC", in O Brasil e a OMC. Curitiba: Juruá, 2002, p. 237.

${ }^{21}$ Documento G/SCM/39, aprovado pelos ministros em Doha acerca de questões e preocupações relativas a aplicação do disposto no art. 27.

${ }^{22}$ VARELLA, Marcelo Dias. Direito Internacional Econômico Ambiental. DelRey: Belo Horizonte, 2003 , p. 153.

${ }^{23}$ De acordo com THORSTENSEN, Vera, a posição do Brasil no comércio internacional é complexa. Considerado um dos grandes interlocutores do comércio internacional, graças à sua posição dentre os
} 
de serem objeto de acordos específicos, demonstram a necessidade de fortalecimento da estratégia de defesa comercial dos países em desenvolvimento e dos menos avançados, inclusive de atuação conjunta, para a consecução de seus objetivos, haja vista que os países mais avançados possuem, via de regra, interesse na manutenção de subsídios nessas áreas, tendo na adoção do discurso liberalizante, levado a efeito medidas que impedem a real abertura em aspectos que julgavam lhes ser prejudiciais.

Na chamada rodada do Desenvolvimento da OMC, realizada em Cancún, houve a criação do grupo G-20 por iniciativa do Brasil, integrado por países em desenvolvimento. $\mathrm{Na}$ oportunidade, o Brasil adotou uma nova estratégia, denominada iniciativa do algodão (cotton initiative), para questionar a concessão de subsídios fornecidos pelos países ricos ao setor agrícola, principalmente a política de concessão de subsídios praticada pelos Estados Unidos aos plantadores de algodão.

Os Estados Unidos, por sua vez, alegaram que o Brasil não poderia questionar os subsídios americanos, porque se comprometeu com a chamada "Cláusula de Paz", pela qual os sócios da OMC decidiram não questionar, até o fim de 2003, os subsídios para produtos agrícolas.

Recentemente, o órgão de solução de controvérsias da OMC deu vitória ao Brasil em uma disputa envolvendo subsídios concedidos pelo governo americano aos produtores de algodão dos Estados Unidos ${ }^{24}$. A disputa foi iniciada em setembro de 2002, quando o Brasil solicitou a realização de consultas perante o governo norte-americano, baseando-se no art. $4^{\circ}, \S 1^{\mathrm{o}}$; art. $7^{\mathrm{o}}, \S 1^{\circ}$ e artigo 30 do ASMC; no artigo 19 do Acordo sobre Agricultura; no artigo XXII do GATT e no artigo $4^{\circ}$ do OSC, que restou infrutífera. Em conseqüência, o Brasil solicitou o estabelecimento de um grupo especial e que o OSC adotasse os procedimentos para a obtenção de informações relativas a caracterização de um grave dano, elencando quais medidas adotadas pelo governo norte-americano deveriam ser investigadas.

As medidas que o Brasil indicou como utilizadas pelos Estados Unidos seriam incompatíveis com disposições do ASMC, do GATT e do Acordo Agrícola por causarem

primeiros vinte países classificados por valor do comércio exterior total, representa apenas $1 \%$ do volume total desse comércio em termos mundiais, possuindo um pauta diversificada de sua exportações e importações, o que o qualifica como um exportador global pequeno, in OMC - Organização Mundial do Comércio.São Paulo: Aduaneiras, 2001, p. 478.

${ }^{24}$ WT/DS267 
prejuízos aos produtores brasileiros de algodão americano (upland), restando configurado, segundo alegado pelo Brasil ajudas em montantes diferentes em campanhas de anos distintos.

Ao condenar os subsídios fornecidos pelo governo norte americano às plantações de algodão upland, a OMC deu um novo norte à política de subsídios adotada por países desenvolvidos, deixando claro que a utilização desse artifício provoca distorções no comércio internacional e prejuízos aos agricultores de países em desenvolvimento e mesmo de países mais pobres, incentivando a utilização do contencioso da $\mathrm{OMC}$ caso não se chegue num acordo na fase de consulta.

A resolução de questionamentos por negociação é interessante para não apenas para os membros reclamantes, mas também para os que se valem da medida, evitando-se uma série de ações judiciais e as custosas indenizações, apesar de alguns países se valerem das consultações para adotar medidas de salvaguardas, causando efeitos danosos as indústrias mais frágeis, suficientes muitas vezes para que essas venham a falir ${ }^{25}$.

$\mathrm{Na}$ verdade, o que se viu foi o início de um processo para se questionar a concessão de subsídios dos países ricos à agricultura, uma das práticas mais tradicionais, protegidas e criticadas no comércio internacional.

Os europeus, criticados na reunião de Cancún por sua resistência em reduzir seus subsídios à agricultura nos níveis reivindicados pelos exportadores, acabaram demonstrando-se simpáticos à iniciativa, destacando a prática de poucos subsídios ao produto, principalmente em áreas como a Grécia e Espanha.

Os norte-americanos reagiram, divulgando tabelas em que admitem as distorções provocadas pelos subsídios ao algodão, argumentando que não são os únicos responsáveis pela redução da demanda mundial pelo produto. Aduziram serem o maior importador mundial, respondendo pela compra no exterior de $80 \%$ de seu consumo, e que, sem esse mercado, os preços cairiam cerca de $11 \%$.

\footnotetext{
${ }^{25}$ Nesse sentido, Varella destaca o caso Estados Unidos - Restrições quantitativas referentes às roupas de baixo provenientes da Costa Rica (WT/DS24/AB/R e WT/DS24/R) e o caso Estados Unidos - medidas que afetam as importações de camisas, blusas de lã e tecidos provenientes da Índia (WT/ DS33/ AB/ R). No primeiro caso os EEUU se valeram das prorrogações cabíveis no procedimento de resoluções de controvérsias para continuar mantendo as medidas de salvaguarda, prazo muitas vezes suficiente para fazer falir indústrias mais frágeis, como de países do Sul. In op. cit., p. 158.
} 
A concessão de subsídios é uma das estratégias utilizadas pelo governo Bush, para angariar mais votos na eleição presidencial daquele país. Restou comprovado pela OMC que o governo norte-americano fornecia subsídios em valores superiores ao dobro permitido pela instituição, o que sem dúvida, afetava os preços internacionais e prejudicava o interesse de países que ofertam o produto, como o Brasil.

$\mathrm{Na}$ verdade, a decisão prolatada nesse caso torna-se paradigmática, eis que foi a primeira oportunidade em que houve uma decisão que não acolhe os argumentos de um país desenvolvido em questão envolvendo a concessão de subsídios internos.

A decisão sinaliza o intuito da OMC em diminuir a desigualdade Norte-Sul, objeto de diversas críticas que alegam a ineficácia e insuficiência das políticas adotadas pela instituição ${ }^{26} \mathrm{em}$ de fato liberalizar o comércio, efetuando justiça social.

A concretização dessa intenção começa a materializar-se no início de agosto, com a celebração de um acordo por diversos países que ocupam posição estratégica na OMC, oportunidade em que se comprometem a efetuar cortes nos subsídios que os países desenvolvidos fornecem para o setor agrícola e à redução de barreiras alfandegárias. Sua realização indica a possibilidade de retomada da Rodada de Doha, tornando possível a continuidade das negociações iniciadas no Qatar, paralisadas desde o encontro ocorrido em Cancun, por força das posições então adotadas pelos países integrantes do G-20.

O desenlace desse tema é fundamental para a efetividade do sistema de comércio mundial. Caso não alcance uma decisão consensual, o próprio futuro da $\mathrm{OMC}$ e a multilateralidade de suas regras estará comprometido.

Outra decisão que demonstra o sentido que a OMC quer dar as suas regras que envolvem à análise de subsídios foi anunciada no dia 04 de agosto próximo passado. Tratase de procedimento inaugurado em 2002, figurando o Brasil como autor, questionamento subsídios existentes na exportação de açúcar europeu. Essa disputa foi iniciada por meio do estabelecimento de consultas pelo Brasil, na qualidade de reclamante. Na ausência de um acordo, resolveu-se apresentar uma queixa à $\mathrm{OMC}$, tendo a Austrália e a Tailândia aderido à posição brasileira, na qualidade de reclamantes.

\footnotetext{
${ }^{26}$ Nesse sentido, veja-se a obra de Marcelo Varella, Direito Internacional Econômico Ambiental. Belo Horizonte: Del Rey, 2001, capítulo IV, p. 141-142.
} 
De maneira diversa do que se viu no caso do algodão, alguns países africanos aderiram às razões de defesa apresentadas pela União Européia, sob o argumento de que qualquer mudança no regime de açúcar da Europa traria prejuízos às suas economias, haja vista deterem acesso preferencial ao mercado europeu. Tal como a decisão tomada no caso do algodão, essa decisão reconhece a existência de subsídios fornecidos por países desenvolvidos e sua desconformidade com os propósitos gerais da OMC.

\section{Medidas Compensatórias}

Para eliminar os efeitos nocivos que os danos ou sua ameaça causem a mercados de países membros atingidos por importações subsidiadas, o Estado membro atingido pode valer-se da aplicação de medidas compensatórias.

As medidas compensatórias serão aplicadas pelo país importador, após a conclusão de processo investigativo em que fique demonstrado além do dano ou ameaça de dano à indústria doméstica e do nexo causal entre as importações subsidiadas e o dano causado (ou ameaça de dano), que os produtos sob investigação são objeto de subsídios acionáveis, devendo o montante de subsídios acionáveis ser superior a um valor de minimis ${ }^{27}$.

Importante destacar, no entanto, que o Estado membro atingido pela importação de mercadorias subsidiadas pode deixar de aplicar medidas compensatórias caso o país exportador comprometa-se a eliminar ou reduzir o subsídio ou adotar outras medidas de efeito equivalente, ou revisar preços para eliminar o efeito prejudicial dos subsídios.

A aplicação de medidas compensatórias será mantida pelo tempo necessário para neutralizar os subsídios que estejam causando dano. A manutenção das medidas deverá ser revisada após um período razoável de tempo ou a pedido de uma das partes interessadas. No entanto, não havendo revisões em período menor que determinem a continuidade das medidas, estas devem cessar após sua imposição por 5 anos.

Durante o período de investigação é possível a aplicação de medida compensatórias provisórias, com duração máxima de quatro meses, caso já tenham se passado 60 dias a contar do início das investigações e que sejam necessárias para evitar a ocorrência do dano, desde que a investigação tenha sido iniciada por comunicação pública, viabilizando a

\footnotetext{
${ }^{27} 1 \%$ para países em desenvolvimento, $2 \%$ para países desenvolvidos e $3 \%$ para países em desenvolvimento que eliminarem seus subsídios à exportação em 8 anos a contar da entrada em vigor do ASCM.
} 
manifestação das partes envolvidas; tenha sido realizada uma avaliação preliminar da existência de subsídio acionável, bem como do e dano que pode causar à indústria doméstica.

A utilização de medidas compensatórias envolvendo o Brasil ocorreu nas disputas envolvendo a concessão de subsídios à exportação no segmento de aeronaves civis em que contendia com o Canadá ${ }^{28}$, bem como nos casos que envolviam a utilização de subsídios nas exportações de coco ralado provenientes de países asiáticos ${ }^{29}$.

\section{Considerações finais}

A política de concessão de subsídios existente em diversos Estados membros integrantes da OMC é um assunto delicado que merece maior atenção das autoridades envolvidas na atividade de defesa comercial e comprometidas com a liberalização comercial.

O processo de globalização dos mercados, agregado ao desenvolvimento tecnológico permite às empresas transfronteiriças utilizarem-se de práticas anticompetitivas para obterem maiores lucros em âmbito mundial, demonstrando a necessidade da existência de normas que tenham por fim coibir práticas anticompetitivas transnacionais, como os cartéis.

A cooperação internacional adequada para que se iniba a utilização dessa prática distorciva em países membros da OMC passa pela criação de um sistema multilateral de defesa da concorrência, com a criação de um sistema supranacional de solução de controvérsias.

A própria $\mathrm{OMC}$ já se preocupa, há muito tempo, em discutir a interação entre defesa comercial e defesa da concorrência, dispondo, inclusive, de Grupo de Trabalho que se preocupa com a implementação de um acordo multilateral a respeito do assunto.

As recentes decisões exaradas pela OMC acerca de subsídios, demonstram que o tema é objeto de preocupação desse organismo internacional, eis que a adoção de figuras anticompetitivas, como os cartéis, também distorce a realidade de mercado, gerando prejuízos comerciais a economias de diversos Estados membros.

\footnotetext{
${ }^{28} \mathrm{WT} / \mathrm{DS} 46$ e WT/DS222

${ }^{29}$ WT/DS22 e WT/DS30 
Isso mostra a necessidade de que temas como defesa comercial e concorrência sejam estudados em conjunto para o pleno desenvolvimento do comércio internacional, evitando a criação de cenários protecionistas, como forma de restringir o acesso de produtos estrangeiros a alguns mercados, ou impedir a aplicação de normas de concorrência a alguns tipos de cartéis, como os cartéis de exportação, devendo o sistema de defesa de concorrência internacional ser elaborado a partir das regras da $\mathrm{OMC}$, aonde a não observância implicaria no estabelecimento de sanções por todos seus membros, o que representa verdadeira exclusão do cenário econômico mundial.

\section{Referências}

1. BARRAL, Welber. Dumping e Comércio Internacional - A regulamentação antidumping Após A Rodada Uruguai. Editora Forense. Rio de Janeiro: 2000.

2. . (org.). O Brasil e a OMC. Curitiba, Juruá, 2002.

3. CASELLA, Paulo e MERCADANTE, Araminta (org.). Guerra Comercial Ou Integração Mundial pelo Comércio? São Paulo: LTr, 1998.

4. CHESNAIS, François. A Mundialização do Capital. São Paulo: Xamã, 1996.

5. FORGIONI, Paula A. Os Fundamentos do Antitruste. São Paulo: Revista dos Tribunais, 1998.

6. HUGON, Paul. História das doutrinas econômicas. São Paulo, Editora Atlas, 1980;

7. HOVENKAMP, Hebert. Federal Antiturst Policy - The Law of Competition an its practice. 2nd. Edition. St. Paul: WestLaw. 1999.

8. JOHANNPETER, Guilherme Chagas Gerdau. Antidumping: prática desleal no comércio internacional. Porto Alegre: Livraria do Advogado, 1986.

9. TREBILCOCK, Michael e HOWSE, R. The Regulation of International Trade. Londres: Routledge, 2001.

10. THORSTENSEN, Vera. Organização Mundial do Comércio. São Paulo: Aduaneiras, 2001, p. 135.

11. VARELLA, Marcelo Dias. Direito Internacional Econômico Ambiental. Belo Horizonte: Del Rey, 2001.

12. WORLD TRADE ORGANISATION. Estados Unidos - Subvenciones Al Algodón Americano (upland). WT/ DS 267/R. Disponível em www.wto.org acesso em junho de 2004.

13.

Brazil - Export Financing Programme for Aircraft. WT/DS 46. Disponível em www.wto.org acesso em outubro de 2004.

14. Canada - Export Credits and Loan Guarantees for Regional Aircraft WT/DS222. Disponível em www.wto.org acesso em outubro de 2004.

15.

Brazil Measures Affecting Desiccated Coconut. WT/DS22. Disponível em www.wto.org acesso em outubro de 2004. 
16.

Brazil Countervailing Duties on Imports of Desiccated Coconut and coconut milk form Sri Lanka. WT/ DS 30. Disponível em www.wto.org acesso em outubro de 2004. 